\title{
Interaction of Two Genes, Fcr and Fcr2, with the $t$ Allele in Common Bean that Restores Color to Flowers
}

\author{
M ark J . Bassett ${ }^{1}$ \\ Vegetable Crops Department, IFAS, University of Florida, Gainesville, FL 32611
}

Additional index words. Phaseolus vulgaris

\begin{abstract}
Plant Introduction (PI) accession 507984 of common bean (Phaseolus vulgaris L.) has partly colored seed coats and either pure white flowers or light laelia flowers. Crosses were made with white-flowered plants of PI 507984: white-flowered plant \#1 $\times$ the genetic stock t ers ers $2 \mathrm{BC}_{2} 5-593$ and white-flowered plant $\# 2 \times$ recurrent parent dry bean breeding line 5593. Inheritance was studied in the $F_{1}, F_{2}$, and $F_{3}$ of the former cross and the $F_{1}$ and $F_{2}$ of the latter cross. PI 507984 (white flower, plant \#1) $\times t$ ers ers $2 \mathrm{BC}_{2} \mathbf{5 - 5 9 3}$ gave $F_{1}$ plants with colored flowers and partly colored seeds. The $F_{2}$ gave a 9:7 segregation ratio (colored flowers to white flowers), and the genetic model proposed is that flower color is restored in the presence of $t / t$ by two complementary genes, $F c r$ and $F c r-2$. That model was confirmed by $F_{3}$ progeny tests of $21 F_{2}$ parents with colored flowers. The cross PI 507984 (white flower, plant \#2) $\times 5$-593 gave an $F_{2}$ segregation ratio of 9:3:4 (bishopsviolet : light laelia : white flowers), indicating that the white-flowered PI 507984 has $v$ lae masked by $t$. Analysis of all the data suggests that PI $\mathbf{5 0 7 9 8 4}$ is heterogeneous at $\mathrm{Fcr}$ and $\mathrm{Fcr}$-2, having all three possible homozygous genotypes, viz., either light laelia flowers from $v^{\text {lae }} t$ Fcr Fcr-2 or white flowers from $v^{\text {lae }} t$ Fcr fcr-2 or $v{ }^{\text {lae }} t$ fcr Fcr-2. The flower color restoration gene in 5-593 is arbitrarily assigned the symbol Fcr. Great variability occurs in partly colored seeds of PI 507984 due to the environment in which the seed was produced.
\end{abstract}

The genetics of partly colored seed coats in common bean and the gene symbol $T$ were first reported by Emerson (1909). The work of Emerson was confirmed by Shaw and Norton (1918). Subsequently, Lamprecht (1935) and Prakken (1934) reported that the substitution of $t$ for $T$ has pleiotropic effects: the flower (in the presence of $P$ and $V$ or $v{ }^{\text {lae }}$ ) changes from colored to white and the seed coat (in the presence of appropriate pattern genes) changes from completely colored (self-colored) to partly colored.

This paper reports the results of an inheritance study of a common bean (P. vulgaris L.) accession that has partly colored seed coats and either white or colored flowers.

\section{Materials and Methods}

Plant Introduction (PI) accession 507984 has determinate habit and partly colored seed. The colored area is a very dark brown with a reddish haze. The seeds of PI 507984 obtained from the USDA Western Regional Plant Introduction Station at Pullman, Wash., (and presumably produced there) had a highly uniform partly colored seed pattern with a broad band of color encircling the hilum (probably broad arcs fused with two large micropile dots), a broad caruncula stripe, a narrow micropile stripe that extends down the entire micropile end of the seed to the dorsal side, and small dots scattered all over the white area of the seed (Fig. 1). When PI 507984 was grown in the greenhouse (15 Sept.-15 Dec. 1989) at Gainesville, Fla., the seeds typically had the partly colored pattern called "major" (Lamprecht, 1934) with large, irregular dots in the white area of the seed coat; the pattern was highly variable

Received for publication 15 June 1992. Accepted for publication 3 Mar. 1993. Florida Agricultural Experiment Station Journal Series no. R-02335. This research was supported in part by a cooperative agreement with the USDA National Program, Horticultural and Sugar Crops, germplasm evaluation funds. The cost of publishing this paper was defrayed in part by the payment of page charges. Under postal regulations, this paper therefore must hereby be marked advertisement solely to indicate this fact.

${ }^{1}$ Professor. from seed to seed on the same plant (Fig. 1). Such a large difference in the expression of the parental genotype of PI 507984 due entirely to environmental effects was unexpected. PI 507984 is heterogeneous with respect to flower color: some plants have pure white flowers and others have the light laelia color characteristic of $v^{\text {lae }}$ (Lamprecht, 1935). Plants with white flowers are not different from plants with light laelia flower color with respect to the pattern of partial coloration of the seed coats or the hue of the colored area, nor does the plant habit show any variation between groups.

Breeding line $t$ ers ers $2 \mathrm{BC}_{2}$ 5-593 was developed by crossing 'Early Wax' snap bean with breeding line 5-593. The gene combination $t$ ers ers 2 from 'Early Wax' was then backcrossed twice into the 5-593 genetic background (Bassett and Blom, 1991). The selection in $\mathrm{BC}_{2}-\mathrm{F}_{2}$ had bipunctata seed pattern, and the selection in $\mathrm{BC}_{2}-\mathrm{F}_{3}$ segregated for homozygosity at ers 2 , giving pure white seed. The cross PI 507984 (white flower, plant \#1) $\times t$ ers ers $2 \mathrm{BC}_{2}$ 5-593 was made and the $F_{1}$ was grown in the greenhouse in Jan. 1990. Notes were made on the flower color of the $F_{1}$ plants and the color and pattern of the seed coat of the $\mathrm{F}_{2}$ seed. The $\mathrm{F}_{2}$ was planted in the field in Apr. 1990, and the plants were tagged for flower colors: white, light laelia $\left(v^{\text {lae }} / v^{\text {lae }}\right)$, cobalt-violet $\left(V / v^{\text {lae }}\right)$, or bishops-violet $(V / V)$. A single seed was taken from each plant and bulked with the other seed from its flower color class. The seed within each of the three flower color classes were classified for color and pattern of partial coloration.

Remnant $\mathrm{F}_{2}$ seed from PI 507984 (white flower, plant \#1) $\times$ t ers ers $2 \mathrm{BC}_{2}$ 5-593 were planted in the greenhouse in Dec. 1990. The $\mathrm{F}_{2}$ segregants with colored flowers were selected for $\mathrm{F}_{3}$ progeny tests that were planted in the field in Apr. 1991. Data were taken on segregation for flower color and seed color patterns.

The cross PI 507984 (white flower, plant \#2) × 5-593 was made in Oct. 1989 and the $\mathrm{F}_{2}$ seed were planted in the field in Apr. 1990. The plants were tagged for flower color as above, and a single seed from each plant was harvested in three separate bulks, corresponding to the flower color of the parent, as above. The seed from each bulk were classified for color and pattern. 


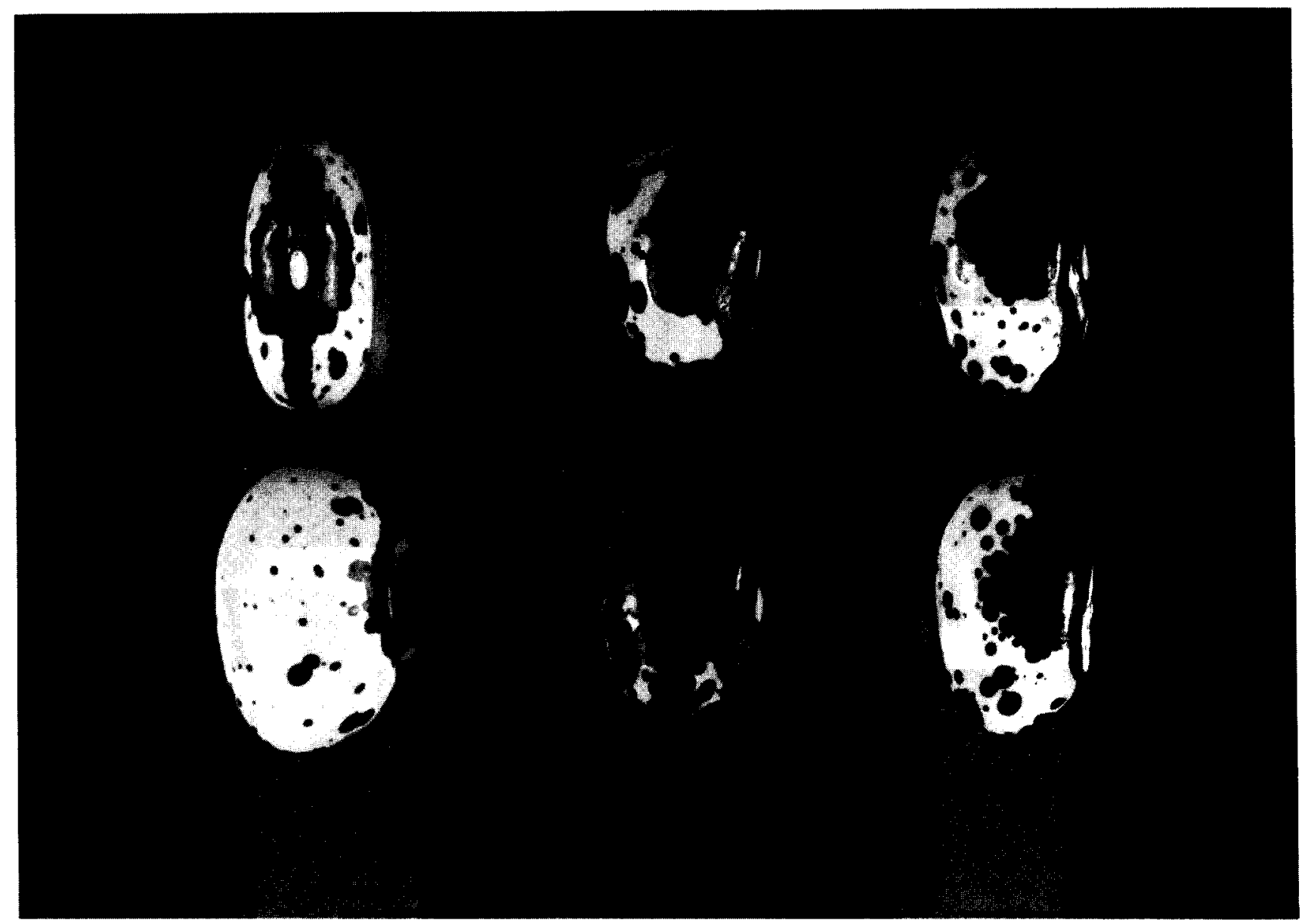

Fig. 1. Partly colored seeds of Plant Introduction accession 507984 grown in two environments. Top left seed and bottom left seed: seeds grown at Pullman, Wash. Top middle and right seeds and bottom middle and right seeds: Four seeds showing the range of variation of partly colored expression when grown in the greenhouse (15 Sept.-15 Dec.) at Gainesville, Fla.

\section{Results and Discussion}

The flowers on the $\mathrm{F}_{1}$ plants from PI 507984 (white flower, plant \#1) $\times$ t ers ers $2 \mathrm{BC}_{2}$ 5-593 were bishops-violet. This result was unexpected because both the parental lines have white flowers due to the $t$ allele. Seed harvested from the F, plants from PI 507984 (white flower, plant \#1) $\times$ t ers ers $2 \mathrm{BC}_{2}$ 5-593 were partly colored (black and the remaining area was white). The colored zones [the "color centers" of Prakken (1972)] included: a strong caruncula stripe, strong arcs on either side of the hilum that did not reach the micropile area, and two large micropile dots that were partly fused. That pattern is similar to the virgarcus pattern of Lamprecht (1934), except that there is no micropile stripe. There were also a few tiny dots widely scattered in the white area. In summary, two parental lines with white flowers and either partly colored seed or white seed known to be the result oft ers ers 2 (Bassett and Blom, 1991) produced $F_{1}$ plants with colored flowers, but partly colored seeds.

My hypothesis is that 5-593 and PI 507984 (white flower, plant \#1) each carry a dominant allele at different genetic loci that can restore flower color in the presence of $t$ by complementary gene action. For simplicity of presentation, I will use schematic symbols arbitrarily assigned to the parents: PI 507984 (white flower, plant \#1) carries $a a B B$ and $t$ ers ers $2 \mathrm{BC}_{2} 5-593$ carries $A A b b$. Thus, the genotype of the $\mathrm{F}_{1}$ will be $t / t A / a B / b$, giving complementation (at $A, B)$ with respect to flower color, but simple allelism at $t$ with respect to partly colored seeds.
The $\mathrm{F}_{2}$ from the cross PI 507984 (white flower, plant \#1) $\times$ t ers ers $2 \mathrm{BC}_{2}$ 5-593 segregated for three flower colors (Table 1). The

Table 1. Segregation for flower color and seed color and pattern in the $F_{2}$ from the cross PI 507984 (white flower, plant \#1) $x$ ters ers $2 \mathrm{BC}_{2} 5-593$.

\begin{tabular}{lcc}
\hline \hline Flower color & Seed color and color pattern & No. plants \\
\hline Bishops-violet & Pure white & 9 \\
& Pure black & 4 \\
& Partly colored & \\
& Dotted testa & 31 \\
& Nondotted testa & 6 \\
Light laelia & Pure white & 1 \\
& Partly colored & \\
& Dotted testa & 5 \\
Pure white & Nondotted testa & 1 \\
& Pure white & 12 \\
& Pure black & 1 \\
Partly colored $^{\mathrm{w}}$ & 12 \\
& Dotted testa & 28 \\
\hline
\end{tabular}

${ }^{2}$ The 57 plants with colored flowers and 53 plants with white flowers give $\chi^{2}(9: 7)=0.878, P=0.35$. When the seven plants with light laelia flowers are considered as a separate class, the $\chi^{2}(27: 9: 28)=5.409, P=0.07$, where the $c^{2}$ component for the $v^{\text {lae }}$ class is 4.636 .

yNo segregation for color; all were black in the colored zones.

${ }^{\mathrm{x}}$ No segregation for color; all were greenish brown in the colored zones. ${ }^{\text {w }}$ Segregated for 29 black and 11 greenish brown in the colored zones. 
genetic hypothesis is that three genes are segregating in the presence of $t / t, v i z$., $V / v^{\text {lae }}, A / a$, and $B / b$. In that model, $A /-B /-$ will restore color to the flowers, whereas $A /-b b, a a B /-$, and $a a b b$ will not (Table 2). Thus, the expected ratio for colored to white flowers is $9: 7$, and the $\chi^{2}(9: 7)=0.878, P=0.35$, giving a good fit to the model (Table 1). However, if one considers the segregation for the hue of the flowers, bishops-violet $(V / V)$ and light laelia $\left(v^{\text {lae }} / v^{\text {lae }}\right)$, the fit is barely adequate, viz., $\chi^{2}(27: 9: 28)=5.409, P=0.07$, where the $\chi^{2}$ component for the $v$ la e class is 4.636 (Table 1). That occurs because the expected frequency is 15.47 and the observed is 7 ; i.e., there is a large deficiency of plants with light laelia flowers that is almost half of the expected. From information provided below, it is apparent that this deviation is unlikely to be random, but probably has a genetic explanation that reduces the observed frequency to exactly one-half of the expected. The question remains whether the loss is the result of changing the expression of $v^{\text {lae }}$ to $V$, or loss of $v^{\text {lae }}$ plants through lethality at some stage of reproduction. Further research is needed to explain this phenomenon.

The only segregation classes not expressing partly colored seeds have either all black or all white seeds (Table 1). The plants with all black seeds are interpreted as segregating for the fully extended color genotype (inheritance unknown) in a $t / t$ background. The plants with all white seeds are the result of segregation for $t$ ers ers 2 that extinguishes (erases) all color formation. The $\mathrm{F}_{2}$ segregation for seed color is 88 colored (or partly colored) : 22 pure white (Table 1). For these two classes the $\chi^{2}(3: 1)=1.467, P=0.23$, which is a good fit. My hypothesis is that PI 507984 (white flower, plant \#1) has the genotype $v{ }^{\text {lae }}$ t Ers ers 2 , in which ers 2 has no effect on color formation in any of the testa zones close to the hilum because of the dominant allele at Ers (Bassett and Blom, 1991). Thus, the $\mathrm{F}_{2}$ segregates 3:1 for Ers/- ers2/ers 2 : ers/ers ers2/ers 2 in a homozygous $t$ background, giving one-quarter white-seeded segregants.

The $\mathrm{F}_{1}$ plants from the cross PI 507984 (white flower, plant \#1) $\times t$ ers ers $2 \mathrm{BC}_{2} 5-593$ set seeds with small black dots in the white areas of the partly colored seed coats. There are only two genes that are reported to produce dotting in partly colored seeds: punc and Mic (Lamprecht, 1940). Breeding line $t$ ers ers $2 \mathrm{BC}_{2}$ 5-593 does not carry either of these genes because no segregation for dotted seed coats was observed in derived generations from the cross 'Early Wax' $\times$ 5-593 (Bassett and Blom, 1991). The dotting expressed in PI 507984 must be controlled by a dominant gene because it appears in the $F_{1}$ with a line not expressing dotting. Thus, the recessive gene punc cannot account for the dotting. The $\mathrm{F}_{2}$ segregated for 48 dotted plants and 35 nondotted (Table 1). For these classes the $\chi^{2}(9: 7)=0.084, P=0.77$. Testing the same classes with $\chi^{2}(3: 1)=13.048, P<0.001$; hence, the $3: 1$ ratio is rejected. All of the nondotted seeds have very restricted partly colored patterns: two points, bipunctata, arcus with two points. Only partly colored patterns that permit color to completely encircle the hilum express dotting. Perhaps the dominant allele at the $Z$ locus must be present for dotting to be expressed.

The identity of the dominant gene, together with $Z$, that controls dotting is uncertain. The Mic gene of Lamprecht (1940) produces a dotting pattern that has its origin at the micropile and extends in an expanding arc downward onto the dorsal portion of the seed, but the dots are scattered randomly in the $\mathrm{F}_{2}$ segregants (from PI 507984) with partly colored seeds. Therefore, the gene is not Mic. The dotting gene in PI 507984 may be another allele at Mic or it may be another locus. The Mic gene is no longer extant in Lamprecht's seed collection, but the $\mathrm{F}_{2}$ from crosses of PI lines 451801 and 451802 with 5-593 segregate for partly colored seeds
Table 2. Genetic model for flower color segregation in the $\mathrm{F}_{2}$ and $\mathrm{F}_{3}$ of the cross PI $507984 t a B v^{\text {lae }} \times t A b V \mathrm{BC}_{2}$ 5-593, where $A$ and $B$ are complementary genes that restore color to flowers in the presence of $t$ and the difference in color produced by $V$ and $v^{\text {lae }}$ is omitted.

\begin{tabular}{lccc}
\hline \hline $\begin{array}{l}\text { Segregation in } \mathrm{F}_{2} \\
\text { Penosed }\end{array}$ & $\begin{array}{c}\text { Expected } \\
\text { frequency }\end{array}$ & Phenotypes & $\begin{array}{c}\mathrm{F}_{3} \text { segregation ratios } \\
\text { for flower phenotypes } \\
\text { (colored : white) }\end{array}$ \\
\hline$t A / A B / B$ & $1 / 16$ & Colored & All \\
$t A / A B / b$ & $2 / 16$ & Colored & $3: 1$ \\
$t A / A b / b$ & $1 / 16$ & White & All \\
$t A / a B / B$ & $2 / 16$ & Colored & $3: 1$ \\
$t A / a B / b$ & $4 / 16$ & Colored & $9: 7$ \\
$t A / a b / b$ & $2 / 16$ & White & All \\
$t a / a B / B$ & $1 / 16$ & White & All \\
$t a / a B / b$ & $2 / 16$ & White & All \\
$t a / a b / b$ & $1 / 16$ & White & All
\end{tabular}

${ }^{\bar{z}}$ All white-flowered $\mathrm{F}_{2}$ segregants are true breeding in $\overline{\mathrm{F}_{3}}$, but among colored-flowered $F_{2}$ segregants the ratio of segregation ratios in $F_{3}$ is $4: 4: 1$ for $9: 7$ to $3: 1$ to all colored.

with the typical dotting pattern of Mic (data not shown). Presumably those PI lines carry Mic.

The $\mathrm{F}_{2}$ from the cross PI 507984 (white flower, plant \#2) $\times 5-593$ segregated for three flower colors-bishop-violet, light laelia, and white-in the ratio 9:3:4 (Table 3). The white flowers are due to $t$ carried by PI 507984. The light laelia flowers are due to $v$ lae, which is also carried by PI 507984, but the flower color of $v^{\text {lae }}$ in PI 507984 is masked by the effect of $t$. Only $25 \%$ of the $\mathrm{F}_{2}$ segregants are expected to be homozygous fort, but they will show partly colored seed coats only in the presence of appropriate pattern genes. Bassett and Blom (1991) established that 5-593 is homozygous for genes that extend seed color; e.g., Bip, Arc, diff, and exp. Thus, not unexpectedly, only eight of the $185 \mathrm{~F}_{2}$ progeny showed partly colored seeds (Table 3), but no explanation can be given for the appearance of partly colored seeds with colored flowers (except tagging errors). Seven of the partly colored seeds were of the "minimus" or "minor" type, and only one had the parental (Floridagrown phenotype) "major" type with strong dotting.

Both PI 507984 (white flower, plant \#2) and 5-593 must have genotype $A A b b$ because, if 5-593 had $a a B B$, then only $7 / 64$ of the $\mathrm{F}_{2}$ segregants would be expected to have white flowers. However,

Table 3. Segregation for flower color and seed color and pattern in the $F_{2}$ from the cross PI 507984 (white flower, plant \#2) $t v^{\text {lae }} \times 5-593 T V$.

\begin{tabular}{lcc}
\hline \hline Flower color $^{2}$ & Seed color pattern & \\
\hline Bishops-violet & Colored & No. plants \\
& Partly colored & 109 \\
& & 112
\end{tabular}

$\begin{array}{llr}\text { Light laelia } & \text { Colored } & 27 \\ & \text { Partly colored } & 29 \\ & & 29 \\ \text { White } & \text { Colored } & 41 \\ & \text { Partly colored } & \underline{3} \\ & & 44\end{array}$

${ }^{\mathrm{z}}$ For the three flower color classes-bishops-violet, light laelia, and white-the $\chi^{2}(9: 3: 4)=1.5072, P=0.47$. For two flower classes, colored (bishops-violet and light laelia combined) and white, $\chi^{2}(3: 1)=0.1459, P$ $=0.70$ and $\chi^{2}(57: 7)=31.34, P<0.001$.

${ }^{y}$ For the two seed pattern classes, colored and partly colored, the $\chi^{2}(15: 1)$ $=1.136, P=0.29$. 
the 57:7 ratio is decisively rejected in favor of the 3:1 ratio of colored flowers to white flowers (Table 3 ). The genetic stock $t$ ers ers-2 $\mathrm{BC}_{2}$ 5-593 cannot have $a a B B$ because previous data from crosses of 'Early Wax' with 5-593 (Bassett and Blom, 1991) fit the ratio 9:7 for colored to white flowers $(T / t, V / v$ selfed) and do not fit the ratio 180:76 for colored to white flowers $(T / t, V / v, A l a, B / b$ selfed) (data not shown). In other words, 'Early Wax' must also have $A A b b$ like 5-593. Thus, PI 507984 (always $t v^{\text {lae }}$ ) is fully heterogeneous at the $A$ and $B$ loci, having all three possible homozygous genotypes: $A A B B$ (light laelia flowers), $A A b b$ (white flowers), and $a a B B$ (white flowers). The hypothesis that PI 507984 white flower plants \#1 and \#2 have $a a B B$ and $A A b b$, respectively, has not been tested further, but the hypothesis that the $F_{1}$ plants from PI 507984 (white flower, plant \#1) $\times$ t ers ers $-2 \mathrm{BC}_{2} 5-593$ have genotype $t A / a B / b$ was tested fully below.

The hypothesis of two complementary factors, $A$ and $B$, that restore flower color in the presence oft was tested in the $\mathrm{F}_{3}$ progeny tests of $\mathrm{F}_{2}$ parents with colored flowers from the cross PI 507984 (white flower, plant \#1) $\times$ t ers ers $2 \mathrm{BC}_{2} 5-593$ (Table 4). Ten of the progenies fit a 9:7 ratio individually, and the combined data for

Table 4. Segregation for flower color in $F_{3}$ progeny tests of $F_{2}$ selections for colored flowers from the cross PI 507984 (white flower, plant \#1) $\mathrm{x} t$ ers ers $2 \mathrm{BC}_{2}$ to $5-593$.

\begin{tabular}{|c|c|c|c|c|c|}
\hline \multirow[b]{2}{*}{ Plot no. } & \multicolumn{2}{|c|}{ Flower color } & \multirow[b]{2}{*}{$\chi^{2}$ ratio ${ }^{y}$} & \multirow[b]{2}{*}{$\chi^{2}$ value } & \multirow[b]{2}{*}{$P$ value } \\
\hline & Colored $^{\mathrm{z}}$ & White & & & \\
\hline $1-138$ & 37 & 27 & 9:7 & 0.064 & 0.80 \\
\hline $1-140$ & 38 & 35 & $9: 7$ & 0.522 & 0.47 \\
\hline $1-143$ & 25 & 16 & 9:7 & 0.372 & 0.54 \\
\hline $1-146$ & 17 & 16 & 9:7 & 0.301 & 0.58 \\
\hline $1-149$ & 26 & 25 & 9:7 & 0.576 & 0.45 \\
\hline $1-150$ & 23 & 20 & 9:7 & 0.133 & 0.72 \\
\hline $1-151$ & 39 & 34 & $9: 7$ & 0.237 & 0.63 \\
\hline $1-153$ & 38 & 22 & 9:7 & 0.300 & 0.58 \\
\hline $1-154$ & 50 & 28 & $9: 7$ & 0.231 & 0.63 \\
\hline $1-155$ & $\underline{37}$ & $\underline{28}$ & $9: 7$ & 0.012 & 0.91 \\
\hline Total & 330 & 251 & $9: 7$ & 0.071 & 0.79 \\
\hline $1-141$ & 42 & 14 & $3: 1$ & 0.00 & 1.00 \\
\hline $1-142$ & 43 & 15 & $3: 1$ & 0.023 & 0.88 \\
\hline $1-144$ & 36 & 17 & $3: 1$ & 1.415 & 0.23 \\
\hline $1-145$ & 48 & 17 & $3: 1$ & 0.046 & 0.83 \\
\hline $1-147$ & 55 & 27 & $3: 1$ & 2.748 & 0.10 \\
\hline $1-148$ & 49 & 20 & $3: 1$ & 0.585 & 0.45 \\
\hline $1-152$ & 53 & 18 & $3: 1$ & 0.005 & 0.95 \\
\hline $1-156$ & 69 & 27 & $3: 1$ & 0.500 & 0.48 \\
\hline $1-157$ & $\underline{66}$ & $\underline{27}$ & $3: 1$ & 0.807 & 0.37 \\
\hline Total & 461 & 182 & $3: 1$ & 3.746 & 0.05 \\
\hline $1-158$ & 51 & 0 & & & \\
\hline $1-159$ & 50 & 0 & & & \\
\hline
\end{tabular}

2Plots 138, 140, 145, and 153 were true breeding for $v^{\text {lae }}$; plots 144,146 , 149,154 , and 156 were true breeding for $V$; plots $141,142,143,147,148$, $150,151,152,155,157,158$, and 159 segregated for $V$ and $v^{\text {lae }}$. Combined segregation data for plots 158 and 159 were 84 bishops-violet and 17 light laelia, giving $\chi^{2}(3: 1)=3.594, P=0.06$.

yThere are $10 \mathrm{~F}_{3}$ progenies that fit a 9:7 ratio, nine $\mathrm{F}_{3}$ progenies that fit a $3: 1$ ratio, and two $\mathrm{F}_{3}$ progenies that are true-breeding. Using the expected ratio of segregation ratios among $F_{3}$ progenies derived from $F_{2}$ parents with colored flowers (Table 2); i.e., $4: 4: 1$, the $\chi^{2}(4: 4: 1)=0.107, P=0.95$. these progenies also give a good fit to a 9:7 ratio. The $\mathrm{F}_{2}$ parents are assumed to have the genotype $A a B b$. Nine of the progenies fit a 3:1 ratio individually, but the combined data give a barely adequate lit to a 3:1 ratio. Much analysis was performed to find another segregation ratio among these nine progenies; e.g., a 2:1 ratio that might be due to a lethal genotype for colored flowers. Although good fits to a 2:1 ratio (due to a hypothetical lethality effect) were found for several of the progenies, no genetic model could be found that is consistent with all the data. I conclude that a more-plausible explanation for the poor fit for the combined data is that there is a weak certation effect that gives a slightly nonrandom assortment of the alleles at one of the two loci restoring flower color; i.e., a surplus of plants with white flowers results from a competitive advantage for pollen tubes carrying either $a$ or $b$. Certation has been reported before in $P$. vulgaris (Bassett et al., 1990). The $\mathrm{F}_{2}$ parents giving 3:1 segregation upon selling are assumed to have one of two genotypes - $A A B b$ or $A a B B$. Two of the $\mathrm{F}_{3}$ progenies are true breeding for colored flowers and are assumed to have the genotype $A A B B$. The ratio of $\mathrm{F}_{3}$ segregation ratios gives a good fit to $4: 4: 1$ for $9: 7,3: 1$, and true breeding for colored flowers, respectively (Table 4). Thus, the genetic model involving two complementary genes restoring color to the flowers in the presence oft is strongly confirmed. I propose the gene symbols $F c r$ and $F c r$ 2 for the schematic genes $A$ and $B$, where $F c r$ represents "flower color restoration." The flower color restoration gene found in 5 593 is arbitrarily assigned the gene symbol Fcr.

Segregation data were not taken for flower color within the colored flower class except for the true breeding plots 1-158 and 1-159 (Table 4). The combined data for these two plots showed a shortage of segregants with light laelia flowers (Table 4), which is similar to the shortage of light laelia segregants seen in the $F_{2}$ (Table 1). No explanation was found for this disturbed segregation.

Data were taken on the segregation for partly colored seed coat patterns for all the $\mathrm{F}_{3}$ plots, and most of the progeny were partly colored (data not shown). No associations were found between partly colored seed patterns and the various segregation ratios for flower color or other variables.

\section{Literature Cited}

Bassett, M.J. and A. Blom. 1991. A new genotype for white seed coat discovered in 'Early Wax' snap bean. J. Amer. Soc. Hort. Sci. 116:131136.

Bassett, M.J., L.B. Xue, and L.C. Hannah. 1990. Flower colors in common bean produced by interactions of the $\mathrm{Sal}$ and $V$ loci and a gametophyte factor $G a$ linked to Sal. J. Amer. Soc. Hort. Sci. 115:1029-1033.

Emerson, R.A. 1909. Inheritance of color in seeds of the common bean,

Phaseolus vulgaris. Nebraska Agr. Expt. Sta. Rpt. 22:65-101.

Lamprecht, H. 1934. Zur Genetik von Phaseolus vulgaris. VIII. Über Farbenverteilung und Vererbung der Teilfarbigkeit der Testa. Hereditas 19:177-222.

Lamprecht, H. 1935. Zur Genetik von Phaseolus vulgaris. XII. Über die Vererbung der Blüten- und Stammfarbe. Hereditas 21:129-166.

Lamprecht, H. 1940. Zur Genetik von Phaseolus vulgaris. XVII-XVIII.

Zwei neue Gene für Abzeichen auf der Testa, Punc und Mip, sowie uber die Wirkung von $V$ und Inh. Hereditas 26:292-304.

Prakken, R. 1934. Inheritance of colors and pod characters in Phaseolus vulgaris L. Genetica 16:177-294.

Prakken, R. 1972. Inheritance of colours in Phaseolus vulgaris L. III. On genes for red seedcoat colour and a general synthesis. Med. Landb. Wageningen. 72-29.

Shaw, J.K. and J.B. Norton. 1918. The inheritance of seed coat colours in garden beans. Mass. Agr. Expt. Sta. Bul. 185:59-104. 